31 AN EVALUATION OF THREE MEASURES OF INFANT TEMPERAMENT

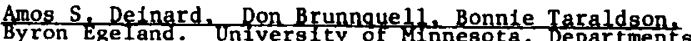
of Psychoeducational Studies and Pediatrics, Box 60, Minneapolis, Innesota

Despite the interest in characterizing the temperament of newborns, there are a relatively small number of techniques ava11able for assessing temperament. Using three approaches to assess temperament - naturalistic observation in the newborn nursery, the Brazelton Neonatal Behavioral Assessment Scale and Carey's Survey of Temperamental Characteristics, an at tempt was made to determine the reliability and the profile of each instrument. One-hundred primiparous mothers and their infants participated in the study. Rellability data from nurses' ratings of inpated in the study. Rellabllity data from nurses' ratings of in-
fants in the newborn nursery were high and there were no differences in ratings over the five days the infants were in the nurs ery. A factor analysis of the scale yielded the following factors: I-Alertness-Activity, II-Contentedness-Soothability, III-Mother Interest and Sk111, IV-Cuddliness, and V-Ease in Caretaking. Using two examiners and testing at seven and ten days of life, the interrater and test-retest reliabliftes of the Brazelton were moderate. The three and $81 x$ month testing with the Carey also ylelded moderate correlations. Comparing components of factors making up the various measures, an alertness, consolability and activity factor seemed to emerge on each Instrument. Organization process measured by the Brazeltion, including ratings of habituation, excitability, irritability, etc., were related to later evaluation by mood by the Carey.

32 LITHIUM RX OF CHILDHOOD MANIC-DEPRESSIVE DISEASE AND ANTISOCIAL BEHAVINR DISORDRRS. G. Robert DeLong:Hosp., Depts. of Pediattics and Neurology, Boston. Eight children (ages 5-15) with serlous behavior disorders responded to lithium carbonate (LI) Rx with dramatic improvement. Aggressive hostile antisocial behavior, and hyperactivity and distractibllity, were common to all. All had various $R x$ over years, Including stimulants, tranquilizers, psychotherapy and environmental modification without satisfactory improvement. All were in stable homes ( 3 adoptive). One group ( 6 pts.) had cyclic behavior; 5 had famlly hx. consistent with manic-depressive disease (M-D); 4 met criterla for both man1a and depression in childhood (Weinberg \& Brumback, Am.J.Dis.Ch。130:380, 1976). Five had disturbances of vegetative or homeostatic functions (hyperphagia, hyperdipsia, excess sweating, salt craving, sleep disorder, etc.) which improved during L1 Rx. Work-up for other causes was negative. The second group ( 2 pts.) had no cyclic changes, no manic behavior, no vegetative disturbances, and no clear family history of affective disorder. In these, L1 was synergist1c with stimulants. L1 serum levels were maintained in accepted range $(0.4-$ $1.0 \mathrm{mEq} / \mathrm{L}_{\mathrm{n}}$ ); no toxicity was seen. Improvement, assessed from function in dally environment, has been malntained 7-25 months (ave. 15 mos.). In $6, \mathrm{~L} 1$ was discontinued with reversion to previous behavior, which improved after restarting L1. LI Rx produces marked and sustained normalization of behavior in some children with severe disorders of mood and affect. It may help elucidate the relationshtps between childhood behavior disorders

GROWTH AND DEVELOPMENT OF CHILDREN BORN TO WOMEN MAIN-

33 TAINED ON METHADONE DURING PREGNANCY. Loretta $P$. Finnegan, Dlan S. Reeser, Rosalind Y. Ting, Martin Rosenzweig, Anne KeTler (Spon. by M. Delivoria-Papadopoulos), Thomas Jefferson University. University of Pennsylvania School of Medicine, Dept. of Pediatrics, Philadelphia, Pa.

Eighty-nine infants (S) born to women maintained on methadone during pregnancy have been evaluated periodically since birth to assess any long term effects of methadone on development and physical growth. Using Gesell's Developmental Schedule, $30 \mathrm{~s}$ had repeated measures between 23 weeks and 52 months, and $59 \mathrm{~s}$ had one measurement between 26 weeks and 41 months. Results show that the score for the first measure of each $S$ ranged between 57 and 121: $43.2 \%$ of the scores fell below 100 with $2.3 \%$ below $75,45.5 \%$ above 100 , and $11.3 \%$ were at 100 . Fifteen $S$ had 3 to 5 repeated measures between 23 weeks and 37 months with no discernible trend over time. Analyses of height and weight were done for 22 of these infants and a control group (C) $(N=18)$ born in the same nursery as $S$ and followed in the hospltal's clinic. The data were put into intervals in weeks: birth: 4-8; 9-13: 14-18: 19-23: 24-28; 29-38. For height, growth curves were parallel suggest in no difference in rate of growth but $C$ was always $h$ igher $(\rho<.025)$. The growth curves for weight were also parallel and there was no significant difference between groups over the study period. In general. the data suggested that infants of women maintained on general. the data suggested that infants of women maintained on regard to growth and development during our study period.

34 WHICH CHILDREN WITH LEUKEMIA DIE AT HOME? Robert P. School of Medicine, Charlot tesvilie, Virginia

In our intensive-care oriented society, death at home for the terminally 111 is an unlikely event. We reviewed the experiences of 27 children with leukemia for whom further remissions were not anticlpated to determine what factors influence the location of the child (home vs. hospital) at the time of death.

Th1rteen (44\%) children in the group died at home. They did not differ from the children who died in the hospital for the following parameters $(p=>.1)$ : age, no. of remissions, size of home town, distance from patient's home to Charlottesville, socio economic status or requirements for supportive care.

The most common medical problems were fever, bone pain, vomiting, headaches and abdominal pain. Bleeding was an infrequent problem. There was no significant difference in the frequency of any of these symptoms in home versus hospital patients.

The only factor that distinguished the groups was the length of time from diagnosis to death. The median survival for 13 children at home was 32 months compared to 18 months for hospitalized ( $<$ <.02).

It is concluded that the location of death for these children is dictated more by personal considerations than medical needs. Although it is not always appropriate, death at home for children with terminal leukemia can be medically and psychologically supported.

\title{
35 PHYSICIAN PREVENTABLE NEONATAL PULMONARY DISEASE IN NEW HAMPSHIRE - 1976
}

Blatman), (Dartmouth Medical School, Department of Materng Saul

Child Health, Vt/NH Reglonal Perinatal Program, Hanover, N.H.).

Physiclan preventable neonatal pulmonary disease was reviewed in all 250 infants admitted to the Dartmouth-H1tchcock Medical Center in calendar year 1976. Data were obtained from the delivering hospital's perinatal records, the neonatal course, and a monthly transport conference case review.

All cases of Respiratory Distress Syndrome or Meconium Aspiration Syndrome were screened for inadequate fetal maturity or gestational age evaluation prior to delivery. Clinical, $x$-ray, and laboratory findings were used fur diagnosis. All cases this year were transported, not inborn.

Results:

RDS associated with: Elective C-section Induced Labor

Meconfum aspiration with inadequate pre- and postpartum management

\section{\# $\quad$ Total Admissions

12

5 \\ $5 \%$ \\ 3}

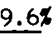

Cost analysis comparing neonatal intensive care expense versus projected fetal maturity study expense for all New Hampshire pregnancies at rlsk supports performing the studies. The conclusion that approximately 10\% of tertiary neonatal intensive care admissions in New Hampshire can be eliminated through adequate fetal gestational age evaluation is being
36 EVALUATION OF THE HOME ENVIRONMENT USING A SELFADMINISTERED QUESTIONNAIRE. William K. Frankenburg,
Esther A. Goldstein and Cynthla Y. Ker. University of Colorado Medical Center, Dept. of Pediatrics, Denver, Colorado A study was conducted to deveiop a brief self-administered questionnaire based on Caldwell's Home Observation for Measures of the Environment (HOME). Previous studies have demonstrated prediction of children's school performance based on home environment (SES) as well as developmental status. The Home Screening Questionnatre (HSQ) could be useful as a screening device for identifying home environments that may be detrimental to early development. Drawing items from two forms of the HOME, two corresponding forms of the HSQ were developed. 180 subjects drawn from private physictans offices (high SES) and public health clinics (low SES) completed the HSQ. Subsequently two examiners conducted Caldwell's interview in each of the subject's homes. Correlations between HOME and HSQ were significant for both Form $0-3$ and $3-6$, ranging from .42 to $.77(p<.01)$. Mean scores on the HSQ and HOME were higher in the private sample than in the clinic sample for all age groups. The distribution for the clinic samples, ages $0-3$ years, was bi-modal, the lower tail ident 1fying scores for the clinic sample was lower than the private both age groups $(0-3$ and $3-6)$. Previous studies have shown the Denver Developmental Screening Test (DDST) to have predictive validity for later school performance. The predictive power of the DDST could be increased if used in conjunction with the HSQ, for children under 6 , to predict school performance and to identify cases where intervention might improve school performance. 